\title{
A CURRICULARIZAÇÃO DA EXTENSÃO NO CURSO DE LICENCIATURA EM FÍSICA DA UNIVERSIDADE DE PASSO FUNDO
}

\section{OUTREACH ACTIVITIES IN THE CURRICULUM OF THE TEACHING DEGREE IN PHYSICS AT THE PASSO FUNDO UNIVERSITY}

\author{
Jucelino Cortez* \\ Luiz Marcelo Darroz** \\ Cleci Teresinha Werner da Rosa*** \\ Alisson Cristian Giacomelli $i^{* * * *}$ \\ Alvaro Becker da Rosa ${ }^{* * * *}$ \\ Carlos Ariel Samudio Pérez ${ }^{* * * * * *}$ \\ Luiz Eduardo Schardong Spalding ${ }^{* * * * * * *}$ \\ Juliano Cavalcant \\ Marivane de Oliveira Biazus $* * * * * * * *$ \\ Marcelo da Silva
}

\section{RESUMO:}

Este artigo tem por objetivo apresentar como aconteçe a curricularização das ações extensionistas desenvolvidas no curso de Física (Licenciatura) da Universidade de Passo Fundo, Rio Grande do Sul. Para tal intento, busca-se destacar o compromisso da Universidade com as atividades de extensão, bem como abordar as orientações governamentais que remetem à inserção dessas acões no currículo dos cursos. A construção também diferencia as várias concepções do caráter extensionista, procurando destacar a visão de extensão universitária como aporte para a formação acadêmica. Na sequência, apresentam-se as atividades desenvolvidas no referido curso, com o objetivo de contribuir para novas discussões e análises em torno deste importante tema para os cursos de licenciatura.

Palavras-chave: Atividade de Extensão; Extensão Universitária; Formação de Professores de Física.

\begin{abstract}
:
This article aims to present the process of inclusion of outreach actions in the curriculum of the teaching degree in Physics at the Passo Fundo University, Rio Grande do Sul. In order to do so, the article tries to highlight the commitment the university has to the outreach activities as well as discuss the government guidelines related to the inclusion of outreach action in the curriculum of undergraduate courses. Another aspect presented in the article refers to the various conceptions of outreach activities, aiming to point out the understanding of university outreach activities as an essential aspect of academic education. In addition, the activities carried out in the aforementioned course are presented aiming to contribute to new discussions and analysis about this important theme for the teaching degree courses.
\end{abstract}

Keywords: Outreach Activities; University Outreach Projects; Physics Teacher Education. 


\section{Introdução}

A Universidade, que atualmente pode ser caracterizada pela indissociabilidade entre o ensino, a pesquisa e a extensão, teve seu berço na Europa medieval, sendo a mais antiga a Universidade de Bolonha, fundada em 1088 (DALBOSCO; FÁVERO, 2017). Essas instituições, por intervenções de papas e de autoridades reais, tornaram-se locais privilegiados onde o ensino estava baseado em atividades de leituras e de debates mediados pelo professor (WANDERLEY, 2003).

Com o passar dos séculos, o conceito de Universidade tomou proporções maiores, com diferentes modelos e propostas, chegando ao ponto de podermos citá-la como um local responsável pela formação científica da sociedade, promovendo a inclusão social, atendendo e estreitando laços com o setor produtivo, fomentando, assim, benefícios que atendam as demandas de sua comunidade (GIMENEZ; BONACELLI, 2013).

Para Motta (2004), a Universidade deve proporcionar um estreitamento entre os conhecimentos acadêmicos que são abordados nas salas de aula, com a realidade onde a mesma está inserida e, portanto, no contexto onde os discentes estão imersos. Ou seja, não basta só oferecer informações em um processo desconectado de contexto e fragmentado. Para este autor, a Universidade deve valorizar sua relação com a sociedade, incentivando uma formação mais qualificada do educando.

Este olhar justifica e reforça a concepção de uma instituição que deve estar fundamentada sobre três pilares indissociáveis: o ensino, a pesquisa e a extensão. Estes, juntos, constituem um processo capaz de promover o pleno desenvolvimento do educando para o exercício da cidadania, capacitando-o para o trabalho (SÍVERES, 2013).

Voltando-se para as atividades extensionistas, é possível mencionar que existem diferentes matizes conceituais sobre o que a extensão universitária deve desenvolver junto aos atores das Universidades e da comunidade. Essas concepções vão desde a visão de transmissão de conhecimento, passando pela noção de voluntarismo sócio-comunitário, chegando à proposição de um processo no qual a Universidade atua na comunidade e esta contribui para a formação dos licenciandos. Tal relação de via dupla entre comunidade e Universidade está nas orientações governamentais de documentos como a Lei ${ }^{\circ} 12.881$, de 12 de novembro de 2013, e no atual Plano Nacional de Educação, de 2014 (BRASIL, 2014). Neste Plano, é pertinente destacar a orientação para a necessidade de projetos e programas de extensão universitária, envolvendo o ensino e a extensão, por meio de um percentual de créditos curriculares.

Para atender estas normativas e desenvolver uma Universidade que atenda e evolua junto à comunidade, tendo nas ações de extensão o viés para essa relação, o curso de Licenciatura em Física da Universidade de Passo Fundo (UPF) vem promovendo diversas atividades relacionadas com os programas de extensão universitária, visando também atender as orientações governamentais atuais.

O objetivo principal deste artigo consiste em divulgar como o referido curso desenvolve os eventos relacionados às ações extensionistas, acreditando que o compartilhamento poderá servir de aporte para reflexões e avaliações sobre a relação entre Universidade e comunidade. Também dentro dos motes do presente trabalho, procura-se imergir, por meio dos referenciais teóricos abordados, nas diferentes formas de conceituar a extensão universitária, justificando este escopo ao se apontarem as orientações de documentos governamentais, como, por exemplo, o Plano Nacional de Educação (BRASIL, 2014).

Para alcançar tais objetivos, o artigo está organizado inicialmente com um resgate teórico sobre a extensão universitária, sobre as normativas governamentais vigentes no viés da curricularização e sobre o perfil das ações extensionistas do curso de Licenciatura em Física da UPF neste cenário. Na sequência, relata-se como o referido curso vem trabalhando com seus atores nas atividades extensionistas, finalizando com algumas considerações pertinentes a este contínuo processo de relação com a comunidade.

\section{A Extensão Universitária e a Curricularização}

Dentre as diversas qualificações que a Universidade possui, no intuito de formar um profissional competente, que atenda as necessidades do contexto onde este está inserido, a mais significativa está pautada na dinâmica da indissociabilidade entre ensino, pesquisa e extensão (SÍVERES, 2013).

A qualidade necessária à Universidade contemporânea, segundo Gimenez e Bonacelli (2013), implica um novo olhar para o seu papel, fazendo com que a Instituição valorize o desenvolvimento de ações empreendedoras, fomentando, assim, melhorias na sociedade. Segundo Rocha (2001), tal desenvolvimento está diretamente relacionado com o caráter extensionista da Universidade, e é preciso entender as diversas matizes conceituais de extensão universitária, no intuito de nortear as ações propostas.

Para Rocha (2001), destacam-se quatro vertentes distintas de conceituação: a primeira, baseada na antiga transmissão vertical do conhecimento, em que a Universidade prestava um serviço assistencialista, sendo esta, na sua própria concepção, a detentora do conhecimento pleno. Nesta forma, o conhecimento acabava por ser restrito a poucas pessoas, ficando dotado de um caráter pouco transformador das realidades do entorno, sendo que, em muitos casos, a Universidade desconhecia a cultura e o saber popular.

A segunda vertente, para Rocha (2001), também é antiga, originária da Idade Média, fundamentada no voluntarismo, possuidora de uma perspectiva mais voltada para as mudanças sociais. Este modelo extensionista evoluiu por meio da relação entre as Universidades e as Igrejas, também ganhando corpo diante de movimentos com perfil ideológico oriundos de militâncias formadas por docentes e discentes. Esta veia tornou-se mais intensa na América Latina, mais especificamente em Córdoba, na Argentina, em 1918, com o Movimento Estudantil de Córdoba. As proposições do Movimento serviram de exemplo para outros de mesmo cunho, sempre procurando 
desenvolver atividades que inserissem o conhecimento gerado nas Universidades dentro da cultura local, procurando transformar a comunidade.

A terceira veia, pautada em ações sóciocomunitárias, é caracterizada por uma visão mais comprometida com as mudanças sociais. Segundo Rocha (2001), este perfil da extensão nasce por volta de 1930, com a participação do governo federal, institucionalizando as ações extensionistas como eventos que primam pela difusão de conhecimentos úteis à solução de problemas sociais. Nesta perspectiva, a Universidade ainda possui um papel de detentora do conhecimento, deixando para a sociedade o papel de receptora de saberes.

A quarta tradição começou a tomar forma na Universidade de Recife, com as ideias de Paulo Freire (VERAS; MENDONÇA, 2009). Este teórico defende que a extensão universitária deve possuir características culturais emancipadoras, proporcionando à Universidade e à comunidade o compartilhamento de saberes, possibilitando a democratização do conhecimento acadêmico junto à sociedade e o trabalho interdisciplinar, relacionando teoria e prática junto ao ambiente universitário (ALMEIDA, 2015).

Corroborando com a quarta matiz, a partir de 1988 a Constituição Federal normatiza a extensão universitária como uma ação indissociável ao ensino e a pesquisa. Esta orientação já serve de indício para um olhar voltado à extensão necessária à formação acadêmica, indo muito além da prestação de serviços que as Universidades realizam na maioria das atividades extensionistas.

Com o Plano Nacional de Educação, iniciado em 2014, os cursos passam a ter as atividades extensionistas como parte integrante dos currículos, cumprindo, assim, a estratégia 12.7, que orienta os cursos a:

[...] assegurar, no mínimo, 10\% (dez por cento) do total de créditos curriculares exigidos para a graduação em programas e projetos de extensão universitária, orientando sua ação, prioritariamente, para as áreas de grande pertinência social (BRASIL, 2014, p. 74).

Assim, com essas diretrizes, fica implícita a curricularização da extensão universitária, compreendendo o currículo como um elo entre os conhecimentos acadêmicos e os contextos sociais. O currículo passa a ser tratado como um ente vivo, em constante transformação e liberdade que uma simples listagem de tarefas e conteúdos não comporta. A concepção de currículo caminha de forma paralela às tentativas de integralizar as práticas pedagógicas que, segundo Motta (2004), são necessárias para que os conteúdos trabalhados na Universidade sejam pensados de uma nova forma, inclusiva $e$ transformadora.

Para Sacristán (1999), o currículo deve sempre estar associado à cultura e à sociedade, relacionando conteúdos acadêmicos às práticas que são possíveis de serem desenvolvidas no ambiente exterior ao meio universitário. Assim, a curricularização da extensão universitária valoriza e prioriza a complexidade do conhecimento, respeitando a integralidade da formação humana e propiciando, junto ao desenvolvimento técnico e científico, valores éticos e cidadãos.
A atual concepção extensionista também é defendida por Rocha (1986), ao afirmar que a extensão possibilita a relação entre a Universidade e o mercado de trabalho, promovendo, assim, a emancipação crítica dos licenciandos. Tal emancipação também é defendida por Freire, ao afirmar que: "o conhecimento não se estende do que se julga sabedor até aqueles que se julgam não saberem" (FREIRE, 1982, p.36).

As ideias emancipadoras de Freire no âmbito da extensão universitária são reforçadas por Carbonari e Pereira (2007). Estes consideram que a extensão tem por obrigação agrandar a relação entre o ensino e a pesquisa, fazendo destes pilares que contribuam para o aprofundamento da cidadania na formação acadêmica.

A nova perspectiva de extensão universitária, defendida por muitos pesquisadores, também está em voga, como já citado, em documentos governamentais vigentes, a exemplo do Plano Nacional de Educação (BRASIL, 2014). Além disso, o Ministério da Educação ainda utiliza o Sistema Nacional de Avaliação da Educação Superior (Sinaes) (BRASIL, 2004), que por meio de seus instrumentos de avaliação institucional, analisa como as Instituições de Ensino Superior (IES) efetivam suas ações extensionistas, bem como a relação entre essas IES e a comunidade onde as mesmas estão inseridas.

\section{A Curricularização da Extensão no Curso de Licenciatura em Física}

A Universidade de Passo Fundo comemora, no ano de 2018, 50 anos de existência. Este meio século pode ser caracterizado pelo envolvimento da Instituição com a comunidade, em uma via de mão dupla, contribuindo para o crescimento da região. Nesta trajetória, norteada pelo tripé ensino-pesquisa-extensão, as atividades extensionistas sempre estiveram presentes na relação com a comunidade, muito antes das proposições de curricularização da extensão.

Imerso neste contexto, o curso de Física (L) da UPF, atualmente com 14 anos, também carrega uma forte característica de envolvimento com a comunidade por meio de suas atividades extensionistas. Esta história teve início em 1966, no curso de Licenciatura em Ciências, quando os professores da área de Física da Universidade deram os primeiros passos ao desenvolverem o ensino desta ciência por meio de abordagens experimentais, utilizando, na maioria das vezes, materiais de baixo custo, uma forma de universalizar o acesso ao uso do laboratório. Estas iniciativas foram desenvolvidas tanto nas disciplinas de Física dos diversos cursos da Universidade, quanto em oficinas e cursos de extensão envolvendo professores da educação básica da região. O ensino de Física, com este viés, tornou-se uma marca da área que foi herdada posteriormente pelo curso, sendo que, no decorrer dos anos, por meio de seus licenciandos e professores, é possível identificar tal vocação em diversos eventos, como Feiras de Ciências, palestras e visitas à UPF promovidas pela própria Universidade ou por escolas de Educação Básica.

Com este compromisso e adequado às novas orientações governamentais, o curso atualmente possui 
um Projeto Pedagógico de Curso (PPC) que contempla, em sua matriz curricular, um total de 3.275 horas, das quais 240 horas são destinadas às atividades extensionistas. Além desta carga horária, os licenciandos também devem desenvolver, conforme as normas do PPC, outras 200 horas em atividades acadêmico-científico-culturais e, neste pacote, 87 devem estar voltadas para a extensão universitária. Segundo o PPC:

[...] a extensão, que é concebida, também, como um
princípio pedagógico essencial ao exercício
profissional docente, estando associada a um conjunto
de ações diluídas na matriz curricular que busca fazer o
acadêmico aproximar-se da realidade social. Nesse
sentido, e cumprindo a exigência mencionada no Plano
Nacional de Educação (PNE), instituído pela Lei no
$13.005 / 2014$, que aponta a necessidade de assegurar no
mínimo $10 \%$ do total de horas do curso em atividades
de extensão, o curso de Física (L) propõe que as 327
horas (correspondentes a $10 \%$ do total de 3.275 horas)
se efetivem através de disciplinas e ações educativas,
sociais e culturais, desenvolvidas por professores e
acadêmicos, interagindo diretamente com as
comunidades. Essa interação direta constitui uma via
de mão dupla para a difusão do conhecimento e para a
interação com as realidades e experiências da
comunidade, resultando em alternativas que
contribuem com a melhoria da qualidade de vida da
população e subsidiam o fazer acadêmico na sua
dinâmica de responder às demandas da sociedade
(UNIVERSIDADE..., 2017, p.9).

Nesta nova proposta, é possível resumir as atividades extensionistas que o curso desenvolve em quatro linhas distintas:

1 - Integração entre disciplinas e cursos de extensão;

2 - Disciplina específica;

3 - Disciplinas com caráter extensionista;

4 - Atendimento às escolas e participação em eventos.

Na sequência, apresenta-se um breve relato de cada uma das quatro modalidades de construção das ações extensionistas desenvolvida pelo curso.

\section{Integração entre disciplinas e cursos de extensão}

A Universidade de Passo Fundo, desde sua fundação, presta diversos serviços junto à comunidade, fazendo, em muitas ocasiões, parcerias com outras instituições de ensino, como escolas estaduais, e ainda com órgãos responsáveis pela educação básica, como as prefeituras. As ações desenvolvidas pelos Institutos da Universidade que estão voltados para a formação de professores, na maioria das vezes, trabalham junto à promoção de cursos de formação continuada para os profissionais da educação básica.

Nesta perspectiva, a área de Física da UPF criou uma tradição, auxiliando professores do ensino básico, valorizando o ensino de Física por meio da experimentação e da construção de equipamentos de baixo custo, facilitando e universalizando o uso do laboratório didático para a abordagem dos mais variados conteúdos de Física.

A partir de 2017, com um novo currículo, o curso de Física passa a oferecer disciplinas que incorporam, em sua matriz, atividades que refletem uma nova concepção de extensão universitária. Estes eventos estão voltados para a construção e o compartilhamento de novos conhecimentos entre os licenciandos do curso e os professores da educação básica, permitindo, assim, significativas contribuições tanto na formação acadêmica, quanto para o contínuo aprimoramento das práticas pedagógicas dos profissionais que já estão inseridos no mercado de trabalho. No atual currículo, o curso oferece as disciplinas de Laboratório Instrumental de Física e Fundamentos de Astronomia. Estas possuem, em sua ementa, orientações para a necessidade da realização de atividades extensionistas.

Paralelamente às disciplinas, o curso de Física também desenvolve projetos com escolas e prefeituras da região, promovendo, junto aos profissionais da educação básica, diversos encontros com temas pertinentes ao ensino e às emergentes estratégias didáticas e pedagógicas. Estes cursos possuem uma carga horária de 40 horas e são desenvolvidos de maneira que metade dos encontros ocorre no município de origem dos professores da educação básica e a outra metade na Universidade. Os encontros nos municípios são organizados pelos professores extensionistas do curso de Física e são por eles desenvolvidos, juntamente com os alunos bolsistas dos projetos de extensão que o curso oferece. Nesses eventos, professores da Universidade, licenciandos e professores da educação básica debatem, entre outros temas, sobre novas estratégias na educação, ferramentas educacionais, utilizando recursos tecnológicos e teorias de aprendizagem.

Já os encontros na Universidade ocorrem de forma concomitante com as mencionadas disciplinas de Laboratório Instrumental de Física e Fundamentos de Astronomia. Nesses momentos, na mesma sala e horário da oferta da disciplina, com a mediação do professor titular, professores da educação básica e licenciandos reúnem-se, a fim de compartilharem saberes em torno das temáticas que fazem parte do currículo, promovendo a possibilidade de uma ação extensionista de duplo alcance, o que promove novos saberes e novas relações para os participantes do curso de extensão e, ainda, possibilita aos licenciandos o diálogo entre teorias abordadas na sala de aula e as práticas vivenciadas no dia a dia dos educadores. Nos encontros, pode-se observar, merecendo destaque, o interesse externado pelos licenciandos, junto aos professores da educação básica por questões sobre as dificuldades e os desafios enfrentados nas escolas.

\section{Disciplina específica}

Outra forma de efetivar a curricularização da extensão, normatizada pelo PPC do curso está no desenvolvimento da disciplina intitulada "Física e Comunidade", que será oferecida no sexto semestre, na qual, segundo a proposta da ementa, os licenciandos deverão analisar a divulgação da ciência e os ambientes onde o processo ocorre, sejam eles formais ou informais. Nas aulas, os licenciandos também terão a oportunidade de vivenciar momentos para discussões sobre experimentos que retratam modelos envolvendo os fenômenos físicos de uma forma lúdica e a viabilidade de construção dos mesmos, em escalas destinadas para um 
grande público. Na sequência das aulas, além das atividades que visam atender à ementa, os licenciandos deverão trabalhar, com a ajuda dos funcionários e estagiários do laboratório, na construção de equipamentos que, posteriormente, mas ainda durante a disciplina, serão utilizados no ponto culminante da disciplina, em um evento denominado "Física na Praça".

Já na oitava edição, o "Física na Praça" é um evento aberto à população em geral, que ocorre uma vez por ano em uma praça pública no centro da cidade de Passo Fundo, entre os meses de outubro e novembro, começando por volta das $19 \mathrm{~h}$, estendendose até às $22 \mathrm{~h} 30 \mathrm{~min}$. Na oportunidade, os estudantes do curso de Física apresentam alguns equipamentos construídos nos laboratórios do curso. Até então, essas atividades não contavam com uma disciplina específica para analisar e abordar o uso de tais ferramentas para o relacionamento entre os fenômenos físicos observados nos experimentos e as situações cotidianas do público presente e, a partir do novo PPC, o curso passa a ter a mencionada disciplina responsável pela elaboração do evento.

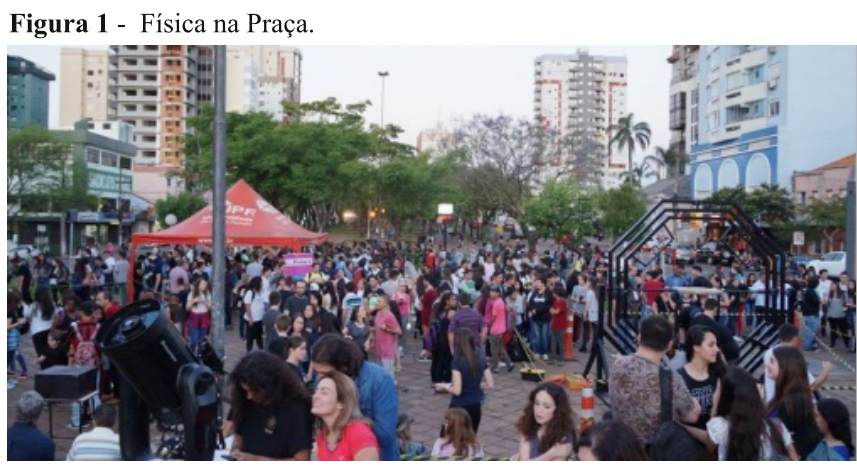

Fonte: Acervo dos Autores.

O caráter lúdico e a interação da comunidade com as atividades experimentais fazem deste evento educacional um acontecimento que atrai famílias e estudantes das escolas do município e da região, cativando crianças e jovens em torno de uma ciência que muitas vezes não é bem recebida pelos estudantes do ensino fundamental e médio.

Também se caracterizam como um grande diferencial do evento a oportunidade de pessoas da comunidade interagirem com os experimentos, sejam elas estudantes ou até leigos em conhecimentos científicos, tornando-os protagonistas nas experimentações, bem como o interesse e a satisfação dos graduandos do curso em discorrer sobre cada equipamento. $\mathrm{Na}$ ocasião, as explicações para cada experimento ultrapassam as barreiras impostas pelas disciplinas, convergindo para um ensino contextualizado e pleno. Conforme o PPC do curso:

$\mathrm{Na}$ preparação das atividades a serem apresentadas no evento, os acadêmicos, juntamente com o professor da disciplina, precisam unir as "fatias" dos conteúdos estudados no curso para significado às atividades científicas apresentadas. Dessa forma, estabelece-se um movimento que busca a superação da disciplinaridade (Universidade de Passo Fundo, 2017, p.56).

\section{Disciplinas com caráter extensionista}

Também com o objetivo de desenvolvimento de uma extensão universitária de mão dupla, que atenda e promova o crescimento, tanto da comunidade quanto dos estudantes do curso, por meio da troca de experiências, as disciplinas de Física Geral e Experimental III, Física Geral e Experimental IV e Ensino de Física III, oferecidas a partir do terceiro semestre, proporcionam um projeto curricular para intervenção na comunidade de origem do licenciando.

No início das disciplinas, quando os estudantes conhecem o plano de ensino, também são orientados a desenvolver um projeto de extensão como parte da ementa. A proposta consiste em orientar cada licenciando a procurar um local de sua escolha, onde exista um ambiente de encontro entre pessoas, como agremiações, clubes, grupo de funcionários de uma empresa ou até mesmo uma associação de moradores. O importante, no caso da Física Geral e Experimental III e IV, é que tal escolha valorize os ambientes informais de aprendizado, não implicando ações a serem desenvolvidas necessariamente numa escola. Sob tal visão, a escola caracteriza-se por ser um ambiente formal de ensino e a inserção nestas realidades já estão a cargo de outras disciplinas do curso.

Com o grupo definido, cada aluno escolhe, a partir de suas afinidades e das necessidades da comunidade, o tema a ser abordado. Os temas são todos na área da eletricidade, no caso da disciplina de Física Geral e Experimental III, e na área de óptica e ondulatória, no caso de Física Geral e Experimental IV, devido ao fato de serem os conteúdos centrais das respectivas disciplinas. Após definidos o grupo de intervenção e o assunto a ser discutido, com o apoio do professor da disciplina, são elaborados materiais instrucionais e experimentos a serem levados para o encontro com a comunidade.

A maioria dos assuntos versa sobre consumo de energia elétrica, produção e transformação de energia, riscos à saúde provocados pela corrente elétrica, história da eletricidade, lentes, defeitos de visão e ondas eletromagnéticas. Todos os temas são muitas vezes polêmicos e instigantes tanto para licenciandos quanto para a comunidade em geral, provocando, segundo relatos dos estudantes, muitas discussões e debates. Em alguns casos, por exemplo, os estudantes encontram nos grupos profissionais que estão ligados à área da eletricidade, tanto com conhecimento científico quanto empírico. Nessas ocasiões, os licenciandos têm a oportunidade de perceber novos olhares e novos modelos para interpretar os fenômenos elétricos abordados na disciplina.

Toda esta atividade proporciona aos licenciandos um crescimento e um interesse pelo conteúdo, melhorando a qualidade das aulas e, assim, potencializando o aprendizado em torno de uma ciência contextualizada e não fragmentada em leis e teorias.

\section{Atendimento às escolas e participação em eventos}

Por fim, a quarta maneira de promoção da extensão universitária reside no atendimento que o curso oferece às escolas de educação básica da região, tanto para visitação dos laboratórios quanto para as palestras sobre Astronomia e as participações do curso em eventos de divulgação científica, como feiras de ciências, nos municípios vizinhos à Universidade. 
Todas estas ações são desenvolvidas pelos alunos bolsistas dos projetos de extensão, que disponibilizam horas para $o$ atendimento que são previamente agendadas junto à secretaria do curso.

Nesses eventos, os bolsistas apresentam equipamentos e experimentos em demonstrações previamente elaboradas e discutidas, acompanhados por professores extensionistas do curso, abordando desde o contexto histórico até as implicações tecnológicas do cotidiano.

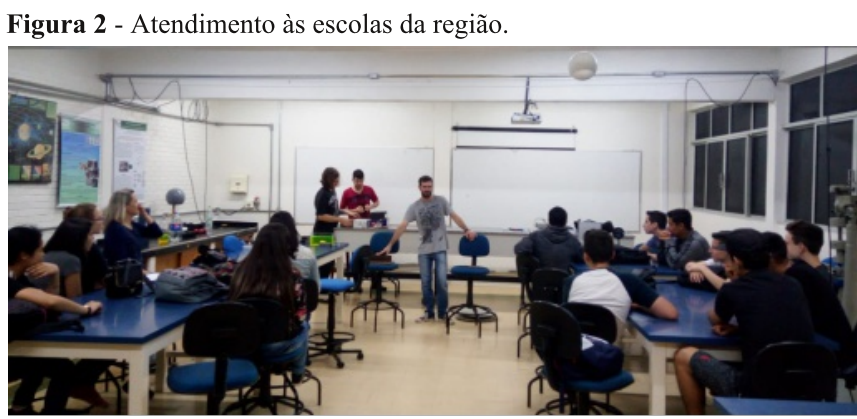

Fonte: Acervo dos Autores.

As práticas extensionistas em questão são voltadas para todas as séries do ensino básico, desde os primeiros anos do fundamental I, até os últimos do ensino médio. Assim, acredita-se também que o curso está dando sua parcela para a desmistificação, criada em muitas escolas, de que a Física é uma disciplina baseada em fórmulas e memorizações de leis e teorias. Também, com esta ação, quando voltada para crianças do fundamental I, por exemplo, procura-se dar os primeiros passos rumo à investigação e a interpretação dos fenômenos físicos. Para muitos estudantes, a Física só começa a fazer parte dos currículos no oitavo ou no nono ano do ensino fundamental, sendo que, dessa forma, é possível despertar nos aprendizes, desde cedo, o gosto por esta ciência, por meio da pesquisa e da experimentação.

\section{Considerações Finais}

A Física desenvolvida nos processos educacionais nas escolas de educação básica caracteriza-se, muitas vezes, por uma proposta memorística e fragmentada, pautada por regras e conceitos que nem sempre estão relacionados com as vivências dos educandos. Segundo Paulo Freire:

\begin{abstract}
As relações educador-educando na escola tradicional são fundamentalmente narradoras, dissertativas, cabendo ao educador a tarefa de "encher" os educandos com os conteúdos de sua narração, numa concepção "bancária" da educação (FREIRE, 2009, p. 67).
\end{abstract}

Ainda, na opinião de muitas pessoas, o gosto pela Física está condicionado a estudantes e professores que possuem um perfil diferenciado dos demais, ficando clara a percepção que muitos têm de uma ciência exclusiva aos cientistas. Ainda referente a esta realidade, Chiquetto afirma que "quanto mais os educandos se exercitam no arquivamento dos depósitos, menos desenvolvem a consciência crítica que os inseriria no mundo como sujeitos" (CHIQUETTO, 2011, p. 6).

Diante desta situação, é possível identificar a grande contribuição que as atividades extensionistas proporcionam tanto para os licenciandos quanto para a comunidade que participa das ações. Percebe-se, durante a sua elaboração e execução, o grande interesse dos universitários e a preocupação que eles têm em entender a Física como uma ciência que está fundamentada na análise dos fenômenos por meio da lógica e da compreensão dos eventos e não no repasse de fórmulas e teorias prontas.

Todas as ações desenvolvidas pelo curso de Física (L) da UPF visam formar um egresso crítico, ético e preparado para os desafios que os processos educacionais impõem junto à formação de uma nova e emergente sociedade. Neste contexto, o professor precisa ter buscado o conhecimento de forma não fragmentada, contextualizando a evolução da ciência e aplicando o referido saber junto àqueles que, na sequência, deverão entender a ciência como algo que está além das disciplinas escolares.

Assim, fica evidenciada a forma com que o curso concebe e procura realizar a extensão universitária, atendendo às constantes buscas pelo aperfeiçoamento na formação, conforme as legislações vigentes e respondendo às necessidades, tanto da sociedade quanto dos licenciandos.

\section{Referências}

ALMEIDA, Luciane Pinho. A Extensão Universitária no Brasil: Processos de Aprendizagem a Partir da Experiência e do Sentido. Dire-Diversité - Recherches et Terrains Limoges, n. 7, 2015.

BRASIL. Lei $\mathrm{n}^{\circ} 10.861$, de 14 de abril de 2004. Institui o Sistema Nacional de Avaliação da Educação Superior SINAES. Diário Oficial da União. Brasília, 2004.

BRASIL. Lei no 13.005 , de 25 de junho de 2014. Diário Oficial da União. República Federativa do Brasil Imprensa Nacional. Brasília, DF, 26 jun. 2014.

BRASIL. Ministério da Educação. Planejando a Próxima Década. Conhecendo as 20 Metas do Plano Nacional de Educação. Diário Oficial da União. Brasília, DF:

Ministério da Educação/Secretaria de Articulação com os Sistemas de Ensino (MEC/Sase), 2014.

CARBONARI, Maria Elisa Ehrhardt; PEREIRA, Adriana Camargo. A Extensão Universitária no Brasil, do assistencialismo à sustentabilidade. Revista de Educação da Anhanguera Educacional, v.10, n.10, 2007.

CHIQUETTO, Marcos José. O Currículo de Física do Ensino Médio no Brasil: Discussão Retrospectiva, Revista ecurriculum, São Paulo, v.7, n.1, 2011.

DALBOSCO, Claudio Almir; FÁVERO, Altair Alberto. Universidade e formação pedagógica: a busca por excelência no ensino, pesquisa e extensão. In: CASAGRANDA, Edison A.; VALÉRIO, Patrícia da Silva; SGARI, Rosani (Org.). Universidade e formação. 1.ed. Passo Fundo: UPF Editora, 2017, p. 13-35.

FREIRE, Paulo. Extensão ou Comunicação? 6.ed. Rio de Janeiro: Paz e Terra, 1982.

FREIRE, Paulo. Pedagogia do oprimido. São Paulo: Paz e Terra, 2009. 
GIMENEZ, A. M. N.; BONACELLI M. B. M. Repensando o Papel da Universidade no Século XXI: Demandas e

Desafios. Revista Tecnologia e Sociedade, Curitiba, v. 9, n. 18, 2013. Disponível em:

http://files.dirppg.ct.utfpr.edu.br/ppgte/revistatecnologiaesoc iedade/revEdEspecialTECSOC2013/revEdEspecialTECSOC 2013_a05.pdf> Acesso em: 26 jul. 2014.

MOTTA, Jorge França. O Papel da Universidade na Formação Social do Educador Reflexivo: Relendo o ensino e a pesquisa na sociedade tecnológica. Revista Acervo, Rio de Janeiro, v. 17, n. 2, p. 111-130, jul./dez. 2004.

ROCHA, Roberto Mauro Gurgel. Extensão Universitária: comunicação ou domesticação? São Paulo: Cortez: Autores Associados: Universidade Federal do Ceará, 1986.

ROCHA, Roberto Mauro Gurgel. A Construção do Conceito de Extensão universitária na América Latina. In: FARIA, Doris Santos de (Org.). Construção Conceitual da Extensão na America Latina. Brasília: Editora UNB., 2001.
SACRISTÁN, J.G. Poderes instáveis em educação. Porto Alegre: Artmed, 1999.

SÍVERES, Luiz. Os processos de aprendizagem na formação e profissionalização docente. Revista Inter-Ação, Goiânia, v. 38, n. 3, p. 649-661, set./dez. 2013.

UNIVERSIDADE DE PASSO FUNDO. Plano Pedagógico do Curso de Física Licenciatura. Passo Fundo. 2017.

VERAS, Dimas B.; MENDONÇA, Djanyse Barros de Arruda. Educação Popular e Reforma Universitária: Paulo Freire e a Criação do Serviço de Extensão Cultural. Estudos Universitários: Revista de Cultura, Recife - PE, n.24, p. 11-21, dez. 2009.

WANDERLEY, L. E. W. O que é universidade? São Paulo: Brasiliense, 2003. 